\title{
Thoughts about the Recruitment Tests in the Planned Settlement of Demobilized Military Officers-Based on the Theory of Justice of John Rawls
}

\author{
Xue Bo ${ }^{1}$ Xue Yan ${ }^{2}$ Li Yongkang ${ }^{3}$ \\ 1 School of Management, Chinese Academy of Governance, P.R. China, 100875 \\ 2 Department of Foreign Languages, Taiyuan Vocational Institute of Tourism, Taiyuan, P.R. China, \\ 030006 \\ 3. School of Public Management, Yunnan University of Economics and Finance, Kunming, \\ P.R.China, 650221 \\ (E-mail: moranlove@126.com , taiyuanxueyan@163.com, $121651831 @ q q . c o m$ )
}

\begin{abstract}
The recruitment tests in the planned settlement of demobilized military officers will be researched in this paper. The method of questionnaire is adopted. Based on the questionnaire results and the perspective of John Rawls' Theory of Justice, some problems on recruitment tests of settlement plan are analyzed, including the recruitment standards are not orderly enough; lax supervision in entering? the settlement system; the information is not open enough; methods and contents of the tests need improving; the examiner team is not qualified enough; too many restrictions in settlement places. Then this paper will put forward strategies how to improve the recruitment tests in the settlement of demobilized military officers. That is, to set up a unified standard of the recruitment tests gradually; to stick to the principle that "whoever can not enter without tests?; to publicize relevant information in a deeper way; to enrich the testing methods and contents; to make further efforts in establishing qualified examiner team and to eliminate restrictions on locations of settlement gradually. At last, it is concluded that the settlement of demobilized military officers will be well settled with strong measures.
\end{abstract}

KeyWords: settlement of demobilized military officers, recruitment tests, Rawls' Theory of Justice, strategy

\section{Introduction}

Since last year, changes began to take place in planned settlement (hereinafter referred to as settlement) of demobilized military officers in central state organs. There was no longer mutual-selection fair, but all officers would take unified written tests. They had to sign up first on the internet, and choose from restricted positions. Such changes have aroused intense responses among demobilized military officers. The recruitment examination work on the planned settlement of demobilized military officers has long been a crucial matter that concerns directly the positions of their employment assigned. Although improvements are starting to occur, there are still some problems affecting successful recruitment examination in the planned settlement of demobilized military officers. This thesis will review relevant issues of recruitment in the settlement from the perspective of Rawls' Theory of Justice.

\section{The Theory of Justice of John Rawls}

According to Rawls, justice is the first and foremost value of social system. His concept of fairness and justice could be summarized as following: all social wealth should be equally distributed, unless there is chance that unequal distribution is in all people's interest.

The first justice principle in Rawls' Theory of Justice is that in people's fundamental freedom system of the widest range, there should be an equal right. And according to the second justice principle, in unequal social and 
economic situations, under agreeable circumstance with the reserve principle of justice, the maximum interest for fewest beneficiaries should be guaranteed (the difference principle); And on equal and fair conditions, statuses and positions should be open to all (the equal principle of fair chance). On this basis, Rawls held that the first principle should be prior to the second one, and the equal principle of fair chance should be prior to the difference principle in the second principle, so that the latter principle could only be taken into account when the former one is given full consideration. Therefore, there come into being two prior principles: one is the priority to social economy, the other being that the justice principle has priority to the efficiency principle, the principle for maximum total profit volume, and the fair chance is prior to the difference principle.

In Rawls' opinion, social justice does not mean that all men are equal. Instead, he proposed the concept of justice in a substantial way. In a more specific way, favorable systems are adopted to make sure that those who gain less benefit could have more interests and opportunities for development, thus social justice in a real sense could be fulfilled
[1]Rawls' Theory of Justice and Fairness has offered sound theoretical support and abundant academic insights for researches of recruitment examination in settlement plans of demobilized military officers in China.

\section{Analyses on Relevant Survey Results}

In around six months, the author made a questionnaire survey among 80 servicemen from 20 central state organs who were settled through planned allocation, thus gained first-hand material through the way. Based on the analysis on the material of how the respondents regard the fairness of recruitment in settlement, it is the author's opinion with the development of the nation's social economy, while present recruitment system in settlement of demobilized military officers is playing a positive role in China's national defense and military modernization, as well as economic and social development, there do exist certain problems which urgently need to take references from favorable experience and practice both home and abroad for constant improvements.



Fig.1: Recruitment test is a proper way to select qualified talents

In Fig.1, in comments toward "Recruitment test is a preferable method for selecting talents, because it is relatively fair on one hand, and could guarantee the talents' fundamental quality", "totally agree" take up $59 \%$ and "agree" amount to $24 \%$, showing support of wide range of demobilized military officers to recruitment tests. 


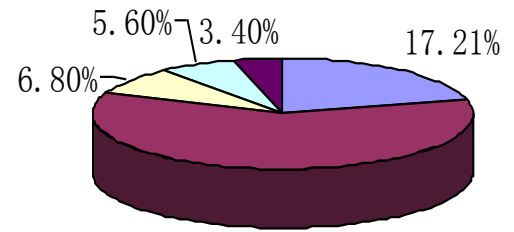

49. $61 \%$ totally approve

$\square$ approve

$\square$ no idea

$\square$ disapprove

totally disapprove

Fig.2 No unified recruitment test for settlement

In Fig.2, in comment toward one important reason for some young officers who are not yet qualified for demobilization leave the army is that there is no unified recruitment test for settlement, and they hope that they could find a good job with the advantage of being young, $61 \%$ voted for approve? and $21 \%$ voted for totally approve?, with a total amount of $81 \%$, meaning that there is vulnerability in present recruitment system in settlement excluding unified tests. The situation is compounded by very rare cases of injustice, which requires our intensive attention.

Statistics of nubber of recruitrent tests mhen seeking job



Fig.3 Number of recruitment tests when seeking job 

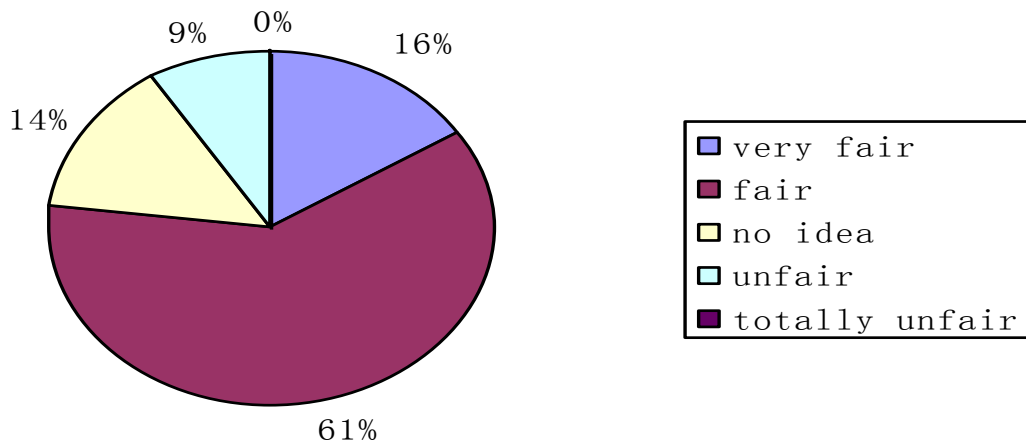

Fig.4 Whether the recruitment tests are fair for demobilized military officer?



Fig.5 The attitude toward the tests

According to Figure1 Data, 6\% of the respondents took only one or two tests. $61 \%$ of them took six to ten tests, and another $10 \%$ took over 11 tests before settling down. Figure1 illustrates that most job tests are separated, as employers organize written test or interviews according to their own needs, while there is no integrated standard. As a result, the demobilized military officers have to rush about a lot in order to take tests of various kinds, which has to cost the officers much time, energy and money, and increases the work load of the employers as well.

In Chart3, among comments to the question Do you think the recruitment tests are fair in central state organs for demobilized military officer?? $77 \%$ of the respondents consider the recruitment tests as very fair or relatively fair, with only $9 \%$ consider the tests as unfair. For the reason, we can see from Chart $4,31 \%$ of demobilized officers chose the lack of a unified test platform is not fair itself? and $32 \%$ of them chose most tests are more of a form instead of real testing so that there is much randomness?. There are as many as $63 \%$ are not satisfied or could not tell clearly the situation of recruitment tests in central state organs, which are relatively fair, indicating that there is much room for improving the recruitment tests of local areas.

\section{4 .Problems Existing in the Present Recruitment Tests of Planned Settlement}

In the planned settlement all over the country, there are generally these methods of settlement: mandatory allocation, quantitative evaluation, integrated method of tests and evaluation, 
settlement by mutual-selection and so on. All these methods have played positive parts in certain period of time. But at the same time, these methods inevitably bear some problems, for example, there could be manipulation, insufficient concern for division and regiment-class officers or meritorious contributors, lack of effective way to measure the officers' contribute to the army, and neglect of the position requirements of the employers. In some cases, the employers would directly contact the demobilized officers to conduct interview, or directly assign positions, which have virtually violated the yardstick of being fair, open and just.

\subsection{The Recruitment Standards Are Not Orderly Enough}

At present, the settlement plans in China are carried out by the unit of province (autonomous region or municipality). The plans are laid out first to the provinces (or autonomous regions and municipalities), and then to local areas of all levels. There is no integrated recruitment standard. As a result, there could be many defects in present settlement system, like lacking qualification standard for applicants and strict control in transferring the applicants to other localities, and there could be faked items in some applicants' files. Take Beijing as an example, the mutual-selection fair before would require both the demobilized officers and employers to come, which could cause too much trouble. Among all those employers, each has its own demands, so that there is too much information for the officers to remember. It is not rare case that an applicant takes pictures of the employers' requirements with a camera in case he forgets. With too many resumes, it is difficult for the employers to select proper applicants for tests. After they settle down the name list, nearly each employer would organize a written test and an interview. The applicants have to rush about a lot to take the tests and interviews, and some of them would even take several physical examinations and blood tests in one single year.

\subsection{Lax Supervision in Entering? the Settlement System}

Establishment of a system does not equal the implementation of it. A small group of demobilized military officers are prone to rely on relationships, which will surely jeopardize the fairness and justice of the employers. Compared with recruitment of civil servants, nepotism or patronage is more common in recruitment process of settlement of demobilized military officers. If this problem is not solved, even if there is an improved and rigorous legal system, the system could only exist on paper.

\subsection{The Information Is Not Open Enough}

The prerequisite of fair play is laid on that every demobilized military officer has the opportunity to share recruitment information equally. To some extent, the openness of recruitment information could reflect the fairness of the recruitment process. In other countries, great attention is always paid to the publication of recruitment information. For example, the recruitment of civil servants in the U.S. [2] has been sticking to public examination and hiring the excellent. Recruitment information is not yet open enough now in China because of various reasons. It not only caused difficulty for the demobilized officers to know in which step are the employers working on, but also harmed the employers' image as being fair and just[3].

\subsection{Methods and Contents of the Tests Need} Improving

Enrichment and innovation in methods and contents of recruitment tests is an inevitable route to scientific development of settlement recruitment in China, and an essential prerequisite as well. For the time being, the methods and contents of recruitment tests are single and dull, and far from being scientific and systematic. It cannot even reach the level of recruitment of civil servants. In some employing units, there is only a written test, which is prone to cases of 揾 igh scores but low abilities?. Some employers would recruit the applicants only through interviews, which has too much randomness. And in others, the test contents are dull, with too much requiring pure memorizing mechanically. All these situations will make it difficult to make the right applicant stand out.

\subsection{The Examiner Team Is Not Qualified Enough}

In any recruitments, the written tests or interviews could not go without a scientific and standardized examiner team. To some extent, the recruitment of excellent demobilized officers is decided by the quality of examiners, especially the interviewers. As interviews have higher subjectivity, the credibility, objectivity and justice of the interview is dependent on the 
quality and level of the interviewers, and the chief interviewer in particular. Now many employing units would select interviews when the interview is already on the way, unaware of the importance of high-quality examiner team. Some employers could not completely eradicate nepotism and some would even make up a team temporarily without effective training.

\subsection{Many Restrictions in Settlement Places}

At present, locations of settlement are often decided by the location of their spouses' household registration. As a result, many excellent officers do not have the chance to be settled in large or medium-sized cities where central state organs are located. Accordingly, before some officers get married, they would choose someone from large cities.

\section{Strategies}

Social justice could only be realized in an effective management system where fruits of social cooperation are distributed according to institutions of the system. Similarly, justice in settlement recruitment is realized by fair system and operational process. To some extent, the justice of recruitment test in a fundamental way has its carrier and prerequisite, which is justice in operational process. When making and implementing recruitment policies, experience and insights should be drew from Rawls' Theory of Justice, to fairly and equally treat every single demobilized military officer. We should not only create opportunities for them to take part in settlement recruitment equally, but make some favorable policies to offer more support and help for vulnerable groups in demobilized military officers[4].

\subsection{Gradually Establish Unified Recruitment Standards}

In order to save resources and make sure the recruitment goes fairly, several standards should be stuck to in the recruitment process. Firstly, standardized criterions should be introduced to qualification review of the applicants. More attention is to be paid to make sure that all applicant information is true. Secondly, the applicants should offer recently-taken photos without hats in order to ensure resolution. At the same time, efforts should be made for the applicants to print the test admission card themselves. Thirdly, all identification credentials should be checked carefully to avoid cheating of any forms.
Fourthly, physical examinations should also follow a unified standard. It is suggested that the office of demobilized officer affairs authorize the employers to organize physical examinations after the name lists for interview are settled down. In this way, the examination results could be retrieved on the internet system. Last but not least, evaluation of applicants transferring to other localities should be taken seriously and the innovation is to be done to the form. If the applicants are transferred to the original troops they have been serving, employers should collect more information about the applicants' shortcomings.

\subsection{Stick to the Principle of anyone Entering the Recruitment System Should Take Tests}

Practice has proved that the principle of 揳 nyone entering the recruitment system should take tests? has played significant role in recruitment tests of civil servants, as this principle has helped eradicate nepotism and carried forward fairness and just, winning support from people of all walks, thus this principle worth a reference in the settlement recruitment. To implement this principle and eradicate nepotism in a fundamental way, we still have to pay attention to two issues. On one hand, power of leaders, especially top leaders of the employing units should be carefully controlled. Leader accountability system should be introduced to the settlement recruitment of demobilized military officers. For those applicants admitted illegally, relevant leaders in the employing units and personnel department should be investigated for responsibility. If it is in serious circumstance, disciplinary actions should be taken to relevant staff. On the other hand, implementation of this principle in public institutions and corporate companies is also endeavor to safeguard the fair rights of demobilized military officers.

\subsection{Information should be Made Public Further}

Only when relevant information is made public in a profound way could fairness and just be realized. On the basis of a safe internet application system, the policies, plans, process and results of settlement should all be open to officers in a macro perspective. And in the micro perspective, efforts should be made to gradually publicize every link of the recruitment on the internet, for example, dos and don'ts of the test, proportion of applicants, 
name list for written tests, result of written tests, name list of interviews, final results, name list for physical examinations, dos and don'ts of physical examinations, name list of qualified applicants in physical examinations, name list of applicants to be transferred to other localities, name list of applicants to be recruited and so on. Among all these items, figure of proportion of applicants should be updated every day so that the applicants could make proper decision. To voluntarily accept supervision from all walks of life and media could make the supervision more effective and deliver truthful information to people, so that more people would be willing to take part in supervision, eliminate changeable factors and increase the transparency of recruitment process.

\subsection{Enrich the methods and content of recruitment tests}

As for testing methods and contents, administrative ability test and essay test could be introduced in written test, and in the interview, there could be structured interview and leaderless group discussion. Besides, there could also be skill tests and psychological tests. On one hand, skill tests could inspect the applicants' degree and ability to use knowledge and intelligence, so as to the speed and quality when treating practical issues. Psychological tests, on the other hand, will evaluate their psychological situation like will, temperament and response, etc. And the indexes could serve as references. Another method worth introducing is called 搒 imulation test?, which will create an environment close to a real one and evaluate comprehensively qualities and abilities of administrating, adapting to the environment, innovation and expression, etc. Specifically, a group formed by lot will be guided by the chief interviewer, organize a panel discussion covering social issues, economy, politics, culture and military affairs, simulate operational work or case handling, drafting official report, receiving visitors and proposing solutions.

\subsection{Establish qualified examiner team}

According to real situation of the demobilized group, we need to establish a scientific and professional examiner team. And we need to pay attention to the following aspects. First of all, appoint examiners of excellent quality. They should not only be equipped with high political awareness and theoretical levels, but also strong ability in comprehensive analysis, induction and deduction, text processing and expression. And most important of all, they should be virtuous, impartial and decent. Next, adopt the right method. Especially when appointing interviewers, they should be selected randomly by lot to avoid nepotism. Specialists from other places could be invited to be interviewers. Besides, the examiners should be trained properly, especially the interviewers, they should accept special trainings (Note: At present, only the interview examiners of recruitment of civil servants can be trained rather than that of recruitment of demobilized officers. When testing, some hold the certificates, which, however, are only the training certificates for the examiners of recruitment of civil servants.). Only those qualified in the training could become interviewers after they are authorized with certificates. It is suggested that the examiner team be formed mainly with specialist, scholars, experienced staff from other agencies, and supported by staff of the employing units, as well as working staff from disciplinary inspection department.

\subsection{Gradually eliminate restrictions in settlement places}

Successful experiences could be drawn from recruitment tests of civil servants in central state organs, to gradually eliminate discriminatory restrictions, restriction in ID registration location for example, so that the officers could have more independent choices for cities, agencies and positions. We could first conduct pilot experiments in central state organs and then to local levels to gradually eliminate discrimination in settlement locations, and promote scientific open recruitment nationwide. All demand information could be accessed on the online registration system, and applicants could choose positions according to their own situations. The name list for interview would be decided by written test results, and qualified applicants would be recruited according to overall score, physical examination result and performance in transferring period.

\section{Conclusion}

The recruitment test in the planned settlement of demobilized military officers has long been a crucial matter that concerns directly the positions of their employment assigned. However, there are still some problems in the 
present recruitment Tests that affected the smooth settlement of demobilized military officers. Based on a questionnaire and years' working experience, the author made some thoughts about the present problems of the recruitment tests and introduced the idea of public testing mechanism in settlement from the perspective of the Theory of Justice of John Rawls. And on the basis of the analysis on the survey and problems, this paper will put forward strategic measures to improve the recruitment tests in the settlement of demobilized military officers. We believe that the settlement of demobilized military officers will be well settled with strong measures from all levels of governments.

\section{References}

[1] John Rawls, Theory of Justice [M]. China Social Science Press, 2002

[2] Chu Bo, Li Xiao, United States Veterans Affairs Management, The first edition, 2007,1 (In Chinese)

[3] Zhu Tingchun, The Enlightenment of the Retired Foreign Military Settlement to Our Country, China Youth News, www.chinanews.com, 2010,9,10

[4] Jiang Jianmin, Value Orientation of Health Policies to Be Promoted in Rural Areas-A Study Based on Rawls'Theory of Justice [J]. Chinese Rural Health Service Administration, 2011, 31(1): 18-19(In Chinese) 